\title{
Adolescents' Experiences of Living with Sickle Cell Disease: An Integrative Narrative Review of the Literature
}

DOI:

10.1016/j.jinurstu.2017.12.008

\section{Document Version}

Accepted author manuscript

Link to publication record in Manchester Research Explorer

\section{Citation for published version (APA):}

Agyeiwaa Poku, B., Caress, A-L., \& Kirk, S. (2018). Adolescents' Experiences of Living with Sickle Cell Disease: An Integrative Narrative Review of the Literature. International Journal of Nursing Studies.

https://doi.org/10.1016/j.jinurstu.2017.12.008

\section{Published in:}

International Journal of Nursing Studies

\section{Citing this paper}

Please note that where the full-text provided on Manchester Research Explorer is the Author Accepted Manuscript or Proof version this may differ from the final Published version. If citing, it is advised that you check and use the publisher's definitive version.

\section{General rights}

Copyright and moral rights for the publications made accessible in the Research Explorer are retained by the authors and/or other copyright owners and it is a condition of accessing publications that users recognise and abide by the legal requirements associated with these rights.

\section{Takedown policy}

If you believe that this document breaches copyright please refer to the University of Manchester's Takedown Procedures [http://man.ac.uk/04Y6Bo] or contact uml.scholarlycommunications@manchester.ac.uk providing relevant details, so we can investigate your claim.

\section{OPEN ACCESS}




\section{Accepted Manuscript}

Title: Adolescents' Experiences of Living with Sickle Cell Disease: An Integrative Narrative Review of the Literature

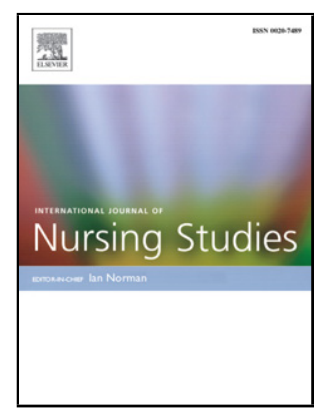

Authors: Brenda Agyeiwaa Poku, Ann-Louise Caress, Susan

Kirk

PII: $\quad$ S0020-7489(17)30283-3

DOI: $\quad$ https://doi.org/10.1016/j.ijnurstu.2017.12.008

Reference: $\quad$ NS 3070

To appear in:

Received date: $\quad 17-5-2017$

Revised date: $\quad 21-12-2017$

Accepted date: $\quad 22-12-2017$

Please cite this article as: Poku, Brenda Agyeiwaa, Caress, Ann-Louise, Kirk, Susan, Adolescents' Experiences of Living with Sickle Cell Disease: An Integrative Narrative Review of the Literature.International Journal of Nursing Studies https://doi.org/10.1016/j.ijnurstu.2017.12.008

This is a PDF file of an unedited manuscript that has been accepted for publication. As a service to our customers we are providing this early version of the manuscript. The manuscript will undergo copyediting, typesetting, and review of the resulting proof before it is published in its final form. Please note that during the production process errors may be discovered which could affect the content, and all legal disclaimers that apply to the journal pertain. 


\title{
Adolescents' Experiences of Living with Sickle Cell Disease: An Integrative Narrative Review of the Literature
}

\author{
Brenda Agyeiwaa Poku ${ }^{a}, \mathrm{MSc}$; Ann-Louise Caress ${ }^{c}, \mathrm{PhD}$; \\ Susan Kirk ${ }^{b}$, PhD
}

${ }^{a}$ Division of Nursing, Midwifery and Social Work, School of Health Sciences, Faculty of Biology, Medicine and Health, University of Manchester, UK, PhD Student

${ }^{b}$ Division of Nursing, Midwifery and Social Work, School of Health Sciences, Faculty of Biology, Medicine and Health, University of Manchester, UK, Professor of Family and Child Health

${ }^{C}$ Division of Nursing, Midwifery and Social Work, School of Health Sciences, Faculty of Biology, Medicine and Health, University of Manchester, UK, Professor of Nursing

*Corresponding author at Division of Nursing, Midwifery and Social Work, School of Health Sciences, Faculty of Biology, Medicine and Health, University of Manchester, UK, Oxford Road, M13 9PL

E-mail: brenda.poku@postgrad.manchester.ac.uk

\begin{abstract}
Background: Sickle Cell Disease is the commonest monogenic haemoglobinopathy worldwide. Living with a long-term condition such as sickle cell disease during adolescence constitutes a significant challenge for the key stakeholders due to the combined effects of chronic illness and adolescent development. For adolescents with sickle cell disease to be cared for and supported appropriately and effectively, it is crucial that health professionals have a comprehensive knowledge and understanding of how adolescents experience living with the condition. While there is developing literature about how adolescent's experience sickle cell disease, this body of research has not been critically reviewed and synthesised.
\end{abstract}


Objective: To identify, critically appraise and synthesise primary research exploring adolescents' experiences of living with sickle cell disease to make recommendations for practice and research.

Design: Integrative narrative review

Data sources: A systematic search of 10 electronic databases and key journals was conducted to identify studies from the inception of databases to September 2016.

Review method: Inclusion criteria: adolescents with sickle cell disease aged 12-19 years, primary data on adolescents' own perspectives, and published in English. Data were extracted on study contexts, methodology/design, theoretical constructs, participants, and key findings. Findings from included studies were synthesised using the integrative narrative approach. Additionally, the methodological quality of studies was assessed using the Hawker et al. (2002) appraisal checklist.

Results: 683 studies were identified, of which 40 fulfilled the inclusion criteria. Nine broad themes emerged: knowledge and understanding of the condition, symptom experiences, self-management, attitude to treatment, healthcare experiences, social relationships, difference and striving for normality, school experiences, and emotional well-being and coping. Majority of the studies were of moderate quality methodologically. Quality assessment demonstrated a high risk of bias in three studies. Conclusions: Sickle cell disease impacts on multiple facets of an adolescent's life. While there are similarities in the experience of living with sickle cell disease and living with other chronic illnesses, there are essential differences in relationship dynamics and healthcare experience. The adolescents expressed less confidence in generic healthcare providers. The review highlights areas relating to symptom management and health service provision that has been under-researched and need further exploration to understand adolescents' experiences and support needs fully. Nursing care and research should focus more on adolescents' developmental wellbeing, promote peer support network among adolescents with the condition and with adolescents with other chronic illnesses and collaborate with adolescents to ensure service development are developmentally and culturally appropriate. 
Keywords: Adolescence, Life Experiences, Literature Review, Sickle Cell Disease, Young People

\section{What is already known about the topic?}

- $\quad$ Previous reviews on adolescent's experience of living with a chronic illness have reported common themes about psychosocial experiences: striving for a normal teenage life, making and maintaining friendships, and experiences of school.

- $\quad$ There is developing literature about how adolescents experience sickle cell disease, but this body of research has not been critically reviewed and synthesised.

\section{What this paper adds}

- $\quad$ Critically appraises and synthesises the international literature about adolescents' experiences of living with sickle cell disease.

- Highlights the importance to adolescents with sickle cell disease of developing a sense of responsibility and social reciprocity, which has not been reported in the broader literature about living with chronic illness during adolescence.

- Identifies a gap in evidence about how adolescents experience and manage sickle cell disease symptoms.

\section{Introduction}

Sickle cell disease (SCD) is the most frequent monogenic haemoglobinopathy worldwide, affecting approximately 20-25 million people, with the majority living in sub-Saharan Africa (Mulumba and Wilson, 2015). Annually, about 300,000 babies are born with the condition worldwide, thus making it a critical public health concern (United Nations General Assembly, 2008). It is estimated that, by 2050 , there will be an increase of $30 \%$ in the number of people with sickle cell anaemia, the most prevalent and most severe form of SCD (Piel et al., 2013).

SCD is characterised by life-threatening and life-limiting consequences such as recurrent painful crises, chronic anaemia, anaemic crises, fatigue, delayed growth/ sexual 
development, increased susceptibility to severe infections, multi-systemic complications, and organ damage. These lead to high mortality and morbidity rates, with significant social and economic impacts (Mulumba and Wilson, 2015). Although bone marrow transplant, together with recent gene therapy has resulted in a cure for a small number of patients in some well-resourced countries, it is not feasible as a global public health approach (Fitzhugh et al., 2014; Ribeil et al., 2017). Instead, it has been recommended that services should provide on-going comprehensive care based on a holistic, multidisciplinary approach to manage the condition and mitigate its complications (Mulumba and Wilson, 2015).

Like all long-term conditions, managing SCD in adolescence constitutes a challenge for the young person, his/her family, and the health providers due to the combined effects of SCD and adolescent development (Suris et al., 2004). While there is developing literature about how adolescent's experience $S C D$, this body of research has not been critically reviewed and synthesised. Consequently, this review aimed to critically appraise and integrate primary evidence on adolescents' experiences of living with SCD, with the purpose of enhancing professionals' knowledge and understanding and making recommendations for clinical practice and future research.

\section{Method}

\subsection{Design}

Given the focus on adolescents' life experiences of SCD, it was important to include both qualitative and quantitative evidence. An integrative review approach was employed. Whittemore and Knafl's (2005) framework for conducting integrative review guided the study. Their framework was selected because it permits a narrative approach to synthesis, which was most appropriate for the aims of the review, and the nature and balance of the evidence included. 


\subsection{Search methods and study selection}

The Centre for Review and Dissemination (2009) systematic guidelines were used to guide the search, screening and selection of literature. Ten electronic databases: CINAHL, MEDLINE, ASSIA, EMBASE, PsyciNFO, British Nursing Index, Web of Science, PubMed, AMED and Global Health were systematically searched (from the inception of databases to September 2016). The Population, Exposure, and Outcome (PEO) framework (Bettany-Saltikov, 2012) was used for identifying and organising the search terms by the key concepts (Adolescent, Sickle Cell Disease, and Experience). An initial scoping search of the major healthcare databases, CINAHL and MEDLINE was conducted to identify optimal search terms. A comprehensive search strategy (Table 1) was developed, which was modified according to the databases. The Boolean operators "OR" and "AND" were used to combine terms within and across the concepts respectively. Online abstract archives of relevant journals (for example, American Journal of Hematology, and Journal of Hematology and Oncology) together with OpenGrey and Open Access Theses and Dissertations were searched. The latter were searched for unpublished studies, and dissertation and thesis abstracts. Finally, a manual search of all reference lists of included studies and relevant reviews was performed to identify additional papers that were not identified in the database searches. Only the first author conducted the literature search and screened potential studies for inclusion; however, the final included studies were agreed upon in a team of three. Searches were unlimited by year, study design or context, provided English versions of articles were available. Four inclusion criteria (Table 2) guided the study selection.

\subsection{Quality appraisal, data extraction and synthesis}

The methodological quality of these studies was appraised, using the Hawker et al. (2002) checklist, which is designed to be used in mixed reviews (Box 1 below and in the supplementary material). Hawker et al.'s tool uses numeric scoring to assess the overall quality of studies. To aid interpretation of scores, we present these as: 'high quality' (satisfactorily reporting on at least seven of the nine dimensions); 'moderate quality' 
(adequately reporting on at least five dimensions); and 'low quality' (satisfactorily reporting on four or fewer dimensions).

\section{Box 1: Hawker et al. (2002) Nine Appraisal Dimensions}

1. Abstract and title

2. Introduction and aims

3. Method and data

4. Sampling

5. Data analysis

6. Ethics and bias

7. Results

8. Transferability or generalizability

9. Implications and usefulness

Data were extracted on the study context, purpose, methodology/design, theoretical construct, participants, and main results by the first author. Due to the varied designs of the included studies, findings were synthesised using a traditional narrative approach, involving thematic analysis.

\section{Results}

\subsection{Search outcome}

A total of 1,205 studies were identified. These were imported to Endnote X5, and fulltext articles of 59 studies were retrieved and screened for inclusion. Full-text articles of three eligible studies could not be located, and none of them was referenced in other studies. Forty studies fulfilled all the inclusion criteria. Figure 1 presents the study identification and selection process.

Figure 1: PRISMA Flow diagram for study identification and selection (adopted after Moher et al. 2009) 


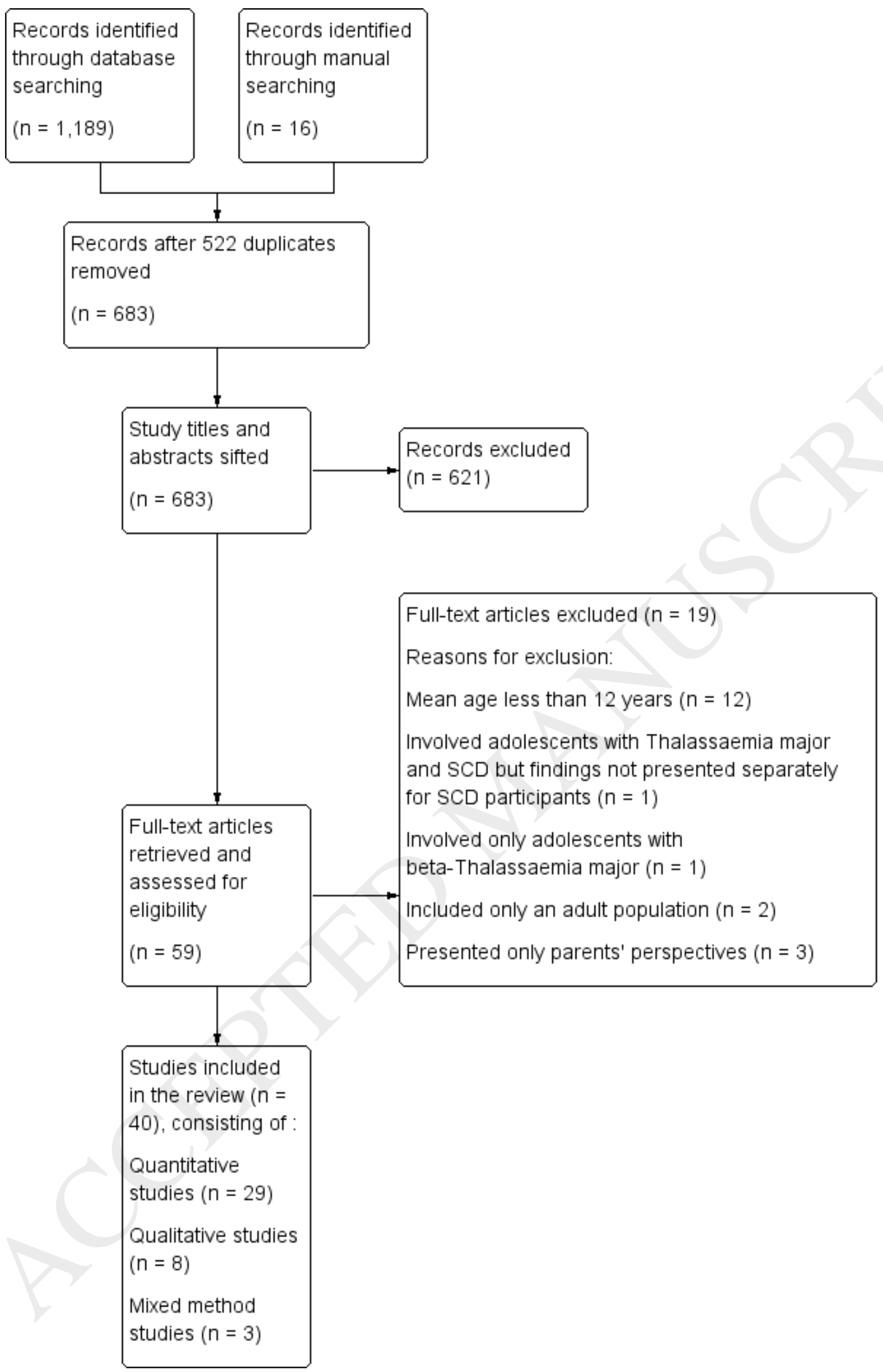

3.2 Study Characteristics and Methodological Quality

The 40 included were conducted in five different contexts: the United States (24), United Kingdom (6), Jamaica (3), sub-Saharan Africa (5) and Middle East (2). Studies were 
published from 1976 to 2016. An overview of the included studies is presented as supplementary material. Almost all the included studies were of moderate to high quality, with only three rated as low. As the low-rated papers contributed different insights, they were included in the review but with their findings treated with caution.

Most the studies provided little or no information regarding recruitment, sampling, sample size calculation, target population, response rates and participants who declined participation, limiting the transparency of authors' assumptions and decisions regarding these elements and creating doubts about the samples' representativeness.

Furthermore, despite the growing recognition of children's rights particularly about their involvement in decision-making and in research that aims to learn about their experiences (Kirk, 2007), all the studies failed to adequately explain how they obtained informed assent/consent and preserved the rights of the adolescent participants.

Moreover, all the quantitative studies were based on relatively small non-random samples, and most employed cross-sectional design; a methodology which may be insensitive to the process of adaptation over time that occurs with chronic diseases. Only one quantitative study provided evidence of sample size calculation (Graves et al., 2016). Moreover, the samples differed regarding age range, disease severity, genotype and phenotype, and family patterns and dynamics. Indeed, most the studies overlooked the potential influence of these factors on their findings. Almost all the included studies involving participants of a wide age range failed to account for differences based on the stages of adolescence. It is notable that nearly all the included studies either failed to discuss their findings in-depth in the context of the studies' geographical, cultural, and healthcare settings or provided insufficient information about the context to enhance the reader's understanding of the results.

Furthermore, several of the included quantitative studies employed generic instruments that are neither child-specific nor age-appropriate nor disease-specific, limiting their sensitivity to the developmental issues of the population. The results reported by the 
majority of the quantitative studies were not tested for statistical and/or clinical significance. Nevertheless, most of the quantitative studies included comparison groups to assess whether the observations reported by adolescents with SCD were different from healthy matched peers and/or the normative adolescent population. All the qualitative studies employed validation checks/multiple analysts to enhance the credibility and trustworthiness of the findings (Shenton, 2004). All the studies used study designs, and data collection and analysis approaches that were appropriate in achieving the studies' aims and objectives, except for one study (John-Olabode et al., 2015). In this study, case notes of adolescents presenting to an emergency department were used retrospectively to assess the level of knowledge and understanding of the condition. Collecting data from adolescents experiencing an acute illness seem an unreliable method for determining knowledge and understanding. It is notable that the mixed method studies presented their qualitative and quantitative data separately. While this facilitated the incorporation of the mixed method data into the other quantitative and qualitative findings, it is unusual for mixed method synthesis.

\subsection{Major themes}

Nine broad themes emerged from the data synthesis process: knowledge and understanding of the condition, symptom experiences, self-management, attitude to treatment, healthcare experiences, social relationships, difference and striving for normality, school experiences, and emotional well-being and coping.

\subsubsection{Knowledge and understanding of condition}

Some evidence exists to suggest that adolescents lack knowledge about SCD, irrespective of geographical, healthcare and cultural context. Adolescents in early and mid-adolescence appear to have limited knowledge and understanding about the disease's inheritance pattern (Bhatt et al., 2011; Erskine, 2011). Among a sample of 117 Jamaican adolescents in late adolescence, a sizeable percentage $(30 \%, n=35)$ perceived their sexual partners as unlikely to have the sickle cell trait, and only $40 \%(n=47)$ were 
knowledgeable of the possible pregnancy complications related to SCD (Bhatt et al., 2011). This limited knowledge and belief may explain the risky sexual behaviours reported in another study involving 122 Jamaican adolescents, where $50 \%(n=61)$ of the sample reported being sexually active, but only a minority $(35 \%, n=43)$ reported using contraception (Asnani et al., 2014). However, none of these quantitative studies tested for the significance of these results.

It also appears that adolescents may lack knowledge about the complications of SCD. In one study, adolescents seemed to identify pain as being the only complication of SCD (Bhatt et al., 2011). Other knowledge gaps appear to be about nutrition and appropriate use of analgesics at home (John-Olabode et al., 2015). In one qualitative study, adolescents identified their information needs as being related to pain management, managing at school and promoting normalcy (White and Mullen, 2004). Studies suggest that adolescents appear to know about general health maintenance measures such as avoidance of strenuous exercise, extreme temperatures, and tobacco use; ensuring regular hydration; and knowing when to seek medical advice (Bhatt et al., 2011; JohnOlabode et al., 2015). The observed knowledge deficit among the adolescents may be because their medical condition and its implications were explained to them as a young child without being revisited in adolescence (Campbell et al., 2010).

\subsubsection{Experiences of symptoms}

Pain related to vaso-occlusion featured predominately in the literature and was the focus of ten studies. Adolescents identified sickle pain as unpredictable, and the defining characteristic of the disease (Erskine, 2011). Evidence suggests that adolescents experience frequent sickle pain of mild intensity, which occurs in different body locations (particularly in the back, chest, abdomen, and extremities), and mostly during rest periods, with each episode lasting an average of five days (Shapiro et al., 1995; Maikler et al., 2001; Dampier et al., 2002; While and Mullen, 2004; Ikefuna et al., 2009). The literature vividly described the incidence, nature and the triggers of painful episodes 
experienced by adolescents, using sensory word descriptors such as "arching", "pounding", throbbing" and "hurting" compared to affective, evaluative and temporal descriptors (Fosdal et al., 2015).

Although the sickle pain was described as unpredictable, it appears to be triggered by known and controllable factors such as strenuous exercise, extremes of temperatures, dehydration, stress, and emotional upset among adolescents (While and Mullen, 2004). Evidence indicates that sickle pain may be the cause of the psychosocial problems experienced by adolescents. Sickle pain was reported to negatively impacted on school attendance and functioning, sleep pattern, daily and social activities, health service use, and health-related quality of life (HRQOL) (Shapiro et al., 1995; Maikler et al., 2001; Brandow et al., 2010; Atoui et al., 2015; Fosdal et al., 2015; John-Olabode et al., 2015; Graves et al., 2016).

Another symptom evident in the literature was fatigue. Although less explored than sickle pain, five studies revealed that it was a challenging symptom of adolescents' daily lives. In one qualitative study, most of the participants described feeling continually tired and unable to carry out activities, wanting to sleep and being unable to concentrate (While and Mullen, 2004). Furthermore, they expressed fatigue-related concerns more than sickle pain. In other studies, adolescents described how fatigue prevented them from engaging in social and school activities, which could lead to being labelled as "lazy" by their peers and teachers (Dyson et al., 2011; Atoui et al., 2015). Some studies, using the Short Form Health Survey (SF36) to examine HRQOL found that compared to their healthy peers, adolescents with SCD had significantly lower scores for vitality or energy level ( $p=0.000$ for both studies) (Amr et al., 2011; Adeyemo et al., 2015). However, the assessment of fatigue by the SF36 is limited to symptom frequency; other dimensions such as severity, emotional or functional impact are unmeasured. Moreover, the form is neither SCD nor an adolescent-specific assessment tool. 


\subsubsection{Self-management}

Most studies examined adolescents' experiences of self-management in relation to pain. No studies explored how adolescents self-manage fatigue. Adolescents were found to manage their painful episodes mostly at home using either pharmacological and/or nonpharmacological measure. In one cohort study, adolescents reported not using medications to control the majority ( $86 \%$ ) of the painful episodes they experience but rather employ only non-pharmacological measures (Shapiro et al., 1995). Contrary to this, in studies where adolescents were using pharmacological means, they were found to mainly take single non-opioid analgesics on an "as required basis" instead of on a regular schedule, rendering the painkillers ineffective (Dampier et al., 2002; Ikefuna et al., 2009). This may explain why almost one-third of adolescents reported persisting or worsening pain which required hospitalisation despite taking analgesics (Dampier et al., 2002; Ikefuna et al., 2009). Evidence suggested that pain intensity and duration, accessibility of analgesics and perceived benefits of medication influenced the decision to take painkillers; and opioid analgesic use increased with increasing age (Dampier et al., 2002).

Four studies revealed that adolescents employ several comfort measures and diversional activities to manage painful episodes (Maikler et al., 2001; While and Mullen, 2004; Barakat et al., 2007; Ikefuna et al., 2009). The commonly mentioned measures were rest and sleep, increased hydration, massage, hot compresses, positioning, prayers, media entertainment, and reading. Some adolescents were also reported to employ active relaxation strategies such as deep breathing and calming self-statements (Barakat et al., 2007). In one cross-sectional study, adolescents in Nigeria reported that their pain was significantly relieved when they used comfort measures together with analgesics rather than using comfort measures or analgesics alone (Ikefuna et al., 2009). These adolescents were reported to rely significantly on comfort measures, and this may be due to the limited availability and access to potent analgesics in poor-resourced contexts like Nigeria. 


\subsubsection{Attitude to treatment}

Only two studies referred to adolescents' attitude towards treatment and treatment adherence. One qualitative study highlighted how differences in adolescents' perception of medical care might influence treatment adherence (Erskine, 2011). While some adolescents valued how drug regimens enable them to control their symptoms which in turn promoted adherence, others' doubts about the efficacy and benefits of preventative treatments such as folic acids and penicillin, led to non-adherence and a preference for using alternative medicine and religion. In an observational study, a sample of 50 Nigerian adolescents was reported not to adhere to their recommended treatment and self-care practices (John-Olabode et al., 2015). Patient beliefs about causes and meaning of illness are fundamental to treatment compliance (Jin et al., 2008) Lay people make sense of chronic disease within the framework of sociocultural context (DennisAntwi et al., 2011). What is notable about the African context is that, although a genetic condition, the cause of SCD is often held by lay people in Africa to lie within the supernatural world (Helman, 2007). Such perspective may influence beliefs and motivations about conventional therapies. Furthermore, the reported non-adherence among the Nigerian adolescents may be due to the limited availability and accessibility of specialised out-patient care to provide continual care and support (Jin et al., 2008). For such adolescents, contacts with healthcare system may only be limited to periods of acute illness. However, this study retrospectively examined case notes of adolescents with SCD presenting to an emergency department, which is not a reliable method for assessing adherence.

\subsubsection{Healthcare experiences}

Only three studies ( 2 from the US and one from the UK) explored adolescents' experiences of health services. In one study, African-American adolescents with SCD described their problematic relationship with healthcare professionals during hospitalisations (Campbell et al., 2010). Painful crises were reported to be discredited, 
underestimated, and undertreated by health practitioners in acute care settings, with adolescents feeling that they were continually defending themselves against accusations of narcotic abuse and addiction (Campbell et al., 2010). Moreover, adolescents felt compelled to actively advocate for themselves to receive optimal care as they perceived that health providers lacked empathy and adequate knowledge and understanding of SCD. This was reported by adolescents who have transitioned to adult services and thus having direct interactions with health professionals. Since SCD is commonest in people of minority ethnic backgrounds in Western countries, the possible explanations for the negative health care experiences are the contextual factors such as racial disparities, and issues of discriminatory attitudes in health services reported by individuals from minority ethnic backgrounds (Anionwu and Atkin, 2001).

On the other hand, adolescents in England described healthcare professionals as "friendly" and "helpful" during out-patient clinic visits (Kemp et al., 2015). Adolescents' dissatisfaction with out-patient clinics was reported to be influenced mainly by long waiting time and lack of waiting room activities (Kemp et al., 2015). In a qualitative study exploring the transition to adult services, adolescents reported a reluctance to leave children's services due to their concerns about adult care providers' knowledge about SCD and therefore their ability to provide optimal care (Porter et al., 2014).

\subsubsection{Social relationships}

Seven studies explored adolescents" relationships with families and peers. Families appear to be a primary source of support, motivation and comfort, enabling adolescents to cope better with SCD. In several studies, mothers and grandparents were identified as primary caregivers and advocates (Dyson et al., 2011; Erskine, 2011; Valenzuela e al., 2013; Atoui et al., 2015; Forrester et al., 2015). However, parental over-protection may create family tension and conflict with adolescents' desire for independence and autonomy (Erskine, 2011; Atoui et al., 2015; Forrester et al., 2015). Furthermore, the family could be seen as a source of guilt. Adolescents were conscious of the physical, 
social, psychological, and economic impact of their illness on their families, leading to feelings of guilt (Atoui et al., 2015).

As a genetic condition, there can be more than one child with SCD in a family. In such households, adolescents described the support received from their siblings with SCD due to their shared experiences (Atoui et al., 2015). In one study, pets were identified as an important source of support (Valenzuela et al., 2013). These studies suggest that having siblings with SCD and pets provide opportunities for relationships where adolescents can care for and support others (rather than vice versa), giving them a sense of responsibility and worth (Valenzuela et al., 2013; Atoui et al., 2015). In one study, adolescents expressed concerns over how SCD might affect future romantic relationships (While and Mullen, 2004).

Adolescents described the benefits of friendships with other young people with SCD regarding shared experiences (Valenzuela et al., 2013). Indeed, formalised peer support was identified as means of making friends, learning new skills, sharing experiences and social reciprocity in relation to giving support to others (Telfair and Gardner, 1999, 2000). One study reported how adolescents could feel an increased sense of empathy for others because of their challenges with SCD (Atoui et al., 2015).

\subsubsection{Self-concept and striving for normality}

Some studies have examined psychological constructs such as self-concept and selfesteem. Some of the early quantitative studies, using the Piers-Harris Self-Concept Scale (which is child-specific) and the Body Cathexis Scale, suggested that adolescents with SCD in early and mid-adolescence were less satisfied with their body and had poorer self-concept compared to their socio-demographically matched healthy peers $(p<0.001)$ (Kumar et al., 1976, Morgan and Jackson, 1986). Factors such as delayed growth and sexual maturity and other physical symptoms such as jaundice and chronic leg ulcers may have accounted for the low self-esteem. 
In a qualitative study conducted in England with eight male adolescents in early and mid-adolescence, participants were preoccupied with their outward appearance and had heightened feelings of self-consciousness about their physique, viewing themselves as deficient in comparison with their peers (Erskine, 2011). However, a qualitative study conducted in Jamaica, including both female and male participants in late adolescence reported positive self-esteem (Forrester et al., 2015). Such observed differences may relate to differences in the stages of adolescence, gender and study context. Other factors that may account for the variations in the self-appraisal, unaccounted for by the studies include the strength of adolescent's social support, their socio-economic and cultural background, and the social construction of the allegedly 'normal' body image (Shakespeare, 1995).

Six studies highlighted how adolescents strive for a 'normal' teenage life. A range of strategies was identified in the literature that adolescents employ to enhance their social image to achieve what they perceive to be normality. For instance, in several qualitative studies, some adolescents reported focusing on shared interests and activities with peers. Others also employed social comparison, a strategy where they enhanced their self-concept by comparing themselves with other people with SCD whose conditions are much worse (Erskine, 2011; Valenzuela et al., 2013; Atoui et al., 2015; Forrester et al., 2015). Moreover, some studies suggested that striving for normality can lead some adolescents in early and mid-adolescence to resist any medical intervention and treatment that they perceive to set them apart from their healthy counterparts (Erskine, 2011; Atoui et al., 2015). Conversely, for those in late adolescence, it may promote treatment adherence and self-care actions to maintain healthily and engage in a 'normal' teenage life (Forrester et al., 2015). It may be that by late adolescence, adolescents have developed the necessary beliefs, knowledge, and skills to manage their illness (Taylor et al., 2008). 
Some studies suggest that striving for normality can lead adolescents to adopt risky behaviours such as having unprotected sex and using alcohol and tobacco to present themselves as 'normal' to others (Britto et al., 1998; Asnani et al., 2014; Forrester et al., 2015). Besides, adolescents may downplay the severity of their illness and resist its social and physical limitations to develop a 'normal' self-presentation (Atoui et al., 2015). However, studies suggest this presentation may be only partially successful, as it can be undermined by events such as severe painful crises, hospitalisations, and death of peers due to SCD (Erskine, 2011; Forrester et al., 2015). Although adolescents with $S C D$, irrespective of geographical location, appear to strive for a 'normal' teenage life and since 'normality' is socially constructed (Freud, 1999), there may be differences in their perception and definition of' normality' due to cultural and geographical differences. This being the case, it is notable that adolescents with SCD from different contexts seem to use similar strategies to attain 'normality'.

\subsubsection{School experiences}

Adolescents' experiences at school were examined in six studies, three of which were conducted in the UK (Anie et al., 2010; Dyson et al., 2010a, 2010b, 2011; Amr et al., 2011; Atoui et al., 2015). These studies discovered that SCD could affect adolescents' ability to concentrate because of fatigue; and led to frequent school absenteeism due to symptoms, hospitalisation, or medical appointments. School absence was reported to result in social exclusion and to negatively impact on educational attainment, which is further compounded by inadequate support structures and low expectations (Dyson et al., 2011; Atoui et al., 2015).

Some UK studies described the challenges adolescents face in maintaining their health in school. For example, being refused toilet breaks, denied access to water during lessons, compelled to engage in strenuous exercises, unable to wear coats in class when cold, and refused rest periods when feeling tired (Dyson et al., 2010b; 2011). Some adolescents felt that teachers viewed their self-care practices as being disruptive to 
school routines (Dyson et al., 2011). Adolescents attributed the onset of sickle pain at school to the hostile school environment and emotional upset arising from the actions of peers and teachers (Dyson et al., 2011). Teachers were seen as lacking empathy and knowledge of SCD (Dyson et al., 2010b). Indeed, the disclosure of the condition to teachers was not felt to improve their school experiences and adolescents preferred nondisclosure as a way of avoiding being singled out by teachers and maintaining normality (Dyson et al., 2011). Studies also suggest that adolescents can experience verbal and physical bullying by both peers and teachers (Anie et al., 2010; Dyson et al., 2010a, 2011). However, studies in Nigeria and Jamaica found that teachers displayed empathy towards adolescents with SCD, exempting them from punishment and school chores (Anie et al., 2010; Forrester et al., 2015). This positive experience may be due to the possible absence of stereotyping in African and Caribbean countries unlike Western countries (Anionwu and Atkin, 2001).

\subsubsection{Emotional wellbeing and coping}

Seventeen quantitative studies examined adolescents' emotional well-being, exploring concepts such as social functioning, depression, anxiety, HRQOL and coping. Several studies suggest that adolescents with SCD may have a higher prevalence of depressive and anxiety symptoms compared to both healthy peers and the normative population (Morgan and Jackson, 1986; Yang et al., 1994; Jerrell et al., 2010; Benton et al., 2011; Lukoo et al., 2015). These studies used mostly generic paediatric scales such as the Child Depression and Anxiety Scale and Multi-Score Child Depression Inventory that are not culturally-tailored. Similarly, compared with adolescents with other chronic illnesses such as spina bifida, diabetes and cystic fibrosis, adolescents with SCD scored significantly higher $(p<0.003)$ on the Beck Depression Inventory, indicating a higher prevalence rate of depression (Key et al., 2001). Caution needs to be applied to these results as their statistical and/or clinical significance is unreported and the tools employed were neither specific for the condition nor age group. 
However, in three studies that used detailed evaluation and psychiatric assessment, higher prevalence rates were not clinically significant (Yang et al., 1994; Benton et al., 2011; Graves et al., 2016). Moreover, in some studies, a significant association was found between the reported higher prevalence rates of depression and anxiety among adolescents with SCD and disease severity, the presence of complications, treatment, and HRQOL $(p<0.001)$ (Jerrell et al., 2010; Graves et al., 2016).

Adolescents with SCD were also found to report significant lower scores on some generic paediatric behavioural measures, including the Child Behaviour Checklist and Student Behaviour Rating Profile (similarly, these tools are not culturally-tailored), compared to their healthy counterparts $(p<0.05)$ (Kumar et al., 1976; Lemanek et al., 1986; Morgan and Jackson, 1986; Hurtig and Park, 1989; Graves et al., 2016). These studies suggest that adolescents with SCD may be at significant risk of behaviour problems such as social withdrawal, hyperactivity, attention deficit, obsessive-compulsive disorder and social phobia compared to their healthy counterparts. However, the scales are not specific for age group or condition.

In comparison with their healthy peers, some studies using the PedsQL scale and SF36 have suggested that adolescents with SCD tend to report significantly reduced overall HRQOL and subscale scores ( $p<0.02)$ (Amr et al., 2011; Dale et al., 2011; Adeyemo et al., 2015; Graves et al. 2016). Overall HRQOL seemed to be influenced negatively by systemic complications $(p<0.017)$ and increased hospitalisation rates $(p<0.04)(A m r$ et al., 2011; Adeyemo et al., 2015). Notably, with regards to the subscale score for the emotional well-being domain on the SF36 form, Arabian and African adolescents reported scores comparable to that of their healthy peers ( $p>0.07$ ) (Amr et al., 2011; Adeyemo et al., 2015). This may be because of the cultural context. HRQOL is a subjective, multidimensional experience that is culturally constructed (Kagawa-Singer et al., 2010). However, none of the studies considered the cultural fit of HRQOL 
dimensions, the conceptual and operational equivalence of the tools across cultures, and the cultural implications on the outcomes.

Spirituality, religiosity, creative activities, and the use of humour were identified as important coping strategies. In one qualitative study, adolescents described using spirituality through their connection with people (e.g. family, friends, and spiritual leaders), nature, and creative activities as a way of coping with painful crises or illness (Clayton-Jones et al., 2016). Additional coping strategies identified were helping others through volunteering activities and the use of humour, particularly about painful crises (Atoui et al., 2015; Clayton-Jones et al., 2016).

Religious beliefs and practices appear to help some adolescents find peace, strength, and comfort, especially during illness or painful crises as well as extending their social support network (Atoui et al., 2015; Clayton-Jones et al., 2016). However, their beliefs could be challenged at times when they felt overwhelmed by SCD or when they reflected on the fairness of having the condition. Unlike Muslim adolescents who view Allah as the ultimate authority on illness and health and accepted their condition as God's ultimate providence, some Christian adolescents felt SCD was a divine punishment (Cotton et al., 2009; Atoui et al., 2015). Epidemiologically, SCD is found mostly in individuals of African, South Asian and Middle Eastern descent (Piel et al., 2013), who are reported to often use religious and spiritual coping strategies (Harrison et al., 2001). Therefore, the use of religiosity and spirituality as coping strategies by the adolescents with SCD reported by the studies may be due to their ethnic and cultural backgrounds, which may be independent of the geographical settings.

\section{Discussion}

This review has identified nine themes in the literature about the experiences of living with SCD in adolescence. One theme central to this study is the process of normalisation, which reflects the conflicts encountered by adolescents as they become 
responsible for their well-being while seeking to develop a sense of identity separate from their illness (Gabe et al., 2002). Some of the strategies used to establish a sense of normality such as social comparison, downplaying disease severity and limitations, nondisclosure of condition, taking risks, treatment non-adherence, and focusing on positives, have been reported by adolescents living with other chronic illnesses (Gabe et al., 2002; Babler and Strickland, 2016; Tunnicliffe et al., 2016). However, in those studies, the concept of "figuring it out" and "accepting the new normal" was essential in attaining normality. These concepts reflect the process of adjustment experienced by adolescents with juvenile arthritis, diabetes, and systemic lupus erythematosus, who may have had a 'normal' life before diagnosis and thus describe their conditions regarding biographical disruptions and seemed to seek for a life comparable to their 'old life'. However, this review discovered that adolescents with SCD strive for a life similar to their healthy peers, which may be influenced by the prevailing sociocultural expectations. Nevertheless, irrespective of the condition, sociocultural context and perception of 'normality', adolescents living with chronic diseases appear to employ similar normalisation strategies.

The review highlighted that adolescents with SCD have a higher risk for behaviour problems, mental health conditions and emotional difficulties, such as depression, anxiety, lower self-esteem, and weaker social skills. Adolescents with other conditions have reported a similar impact on their psychosocial wellbeing (Mackner et al., 2004; Jamieson et al., 2014). The evidence suggests that family, friends, siblings, and pets are essential aspects of adolescents' social support networks, with each group playing a different role in helping the adolescent adjust to their condition. While family provides support oriented towards all aspects of the adolescent's everyday life, peers provide support grounded in the experience of growing up. However, adolescents expressed ambivalent feelings towards their interactions with families and peers and the support they provide. These findings are consistent with the views expressed by adolescents with other chronic conditions about their social support networks (Kyngäs, 2004; Rhee et al., 
2007; Taylor et al., 2013; Jamieson et al., 2014; Mufti and Cartwright, 2015; Jayarajah, 2016 ;). The benefits of friendships with peers with SCD have been similarly reported in asthma, epilepsy, juvenile rheumatoid arthritis, and diabetes (Kyngäs, 2004).

While there are similarities between the experience of living with SCD and that of other chronic illnesses, there also appear to be substantial differences in relationship dynamics when compared with the literature about adolescents with other chronic conditions. There is evidence to suggest that adolescents with SCD express a sense of responsibility and desire for reciprocal relationships, which is often complicated by social isolation and rejection perpetuated by SCD and its symptoms and complications. The review suggests that adolescents strive to satisfy this desire either by supporting and caring for their siblings with SCD, their pets, and other individuals with SCD through peer support groups or engaging in volunteerism.

Moreover, the review revealed that health professionals and the care environment could play a significant role in adolescents' experience of healthcare. Acute care for adolescents with SCD continues to be delivered in non-specialised units. On these units, there is evidence to suggest that professionals can be viewed by adolescents as unempathetic and possess insufficient knowledge of SCD compared to health practitioners at specialist out-patient clinics who are seen as supportive and experts in the condition.

\section{Implications for nursing practice and research}

Adolescents' with SCD appear to have life challenges, desires and needs characteristic of adolescence. Therefore, rather than focusing on the illness, nursing care should concentrate more on adolescents' developmental wellness (Taylor et al., 2008). Moreover, the review highlights the significant role of the care environment in adolescents' health service experiences. Providing dedicated adolescent and young 
person SCD acute care units could enhance care and adolescents' experience of healthcare. Existing literature on the healthcare experiences of adolescents with cancer supports this (Taylor et al., 2013). Beside SCD, the geographical, cultural, and healthcare contexts characterise adolescents' life and impact on their experiences. These social factors account for the differences observed in the experiences. Therefore, it is crucial that service development and improvement be co-designed and planned with adolescents to ensure that they are developmentally, contextually and culturally appropriate. Furthermore, the review indicates that adolescents with SCD employ comparable normalisation strategies irrespective of geographical and cultural background. This may be helpful when developing interventions for adolescents with SCD in Western countries, who come from diverse minority ethnic backgrounds.

Furthermore, adolescents with SCD appear to have a greater sense of responsibility and social reciprocity, desiring opportunities to 'give back' and support others. Nurses can draw on this and promote connections among adolescents with SCD as well as between them and adolescents with other chronic illnesses. Such peer support networks have the potential to create opportunities for adolescents with SCD to receive from and provide support and understanding to others. The review suggests that adolescents use volunteerism as a means to satisfy their desire for social reciprocity. Therefore, opportunities should be created for adolescents to volunteer, facilitate and participate in service development, social interventions and healthcare research. Having such opportunities may enhance their self-esteem, self-worth, and social interactions, which are significantly affected negatively by the condition. It is also important to ensure adolescents' mental health needs are regularly monitored and interventions provided to promote their emotional wellbeing.

Most of the extant literature on symptoms experiences have focused on sickle pain and its management. There are consequently gaps in knowledge relating to adolescents' experiences of living with other symptoms associated with SCD such as fatigue, chronic 
leg ulcers and the physical manifestations of jaundice. Research about living with these symptoms is needed to enhance our understanding of adolescents' experiences of SCD. Moreover, many fundamental aspects of adolescents' life such as their attitude to treatment, the experience of health services, including hospital care and relationship with health professionals, their support needs, and perceptions about the future should be considered in future research. Furthermore, participants' characteristics (age, gender, family dynamics, and socioeconomic status) should be factored into the analysis of further studies. One of the critical weaknesses of the reviewed papers was the limited consideration of culture, geography and the healthcare contexts. The reviewed studies adopted a more clinical and psychological perspective to adolescents' experience, giving less attention to the implications of the adolescents' socio-cultural context. Therefore, future research should consider the role of contextual factors such as culture on adolescents' experiences.

\section{Conclusion}

The strength of this review lies in the integrative review methodology adopted to gain a broader perspective on the research topic by integrating quantitative, qualitative and mixed methods studies. Using Whittemore and Knafl's (2005) method provided a systematic approach to the review. However, the nature and balance of the included evidence and the depth of the included data limited the analytic depth of the synthesis. Another limitation of this review is that only the first author assessed the inclusion of potential studies and conducted the quality assessment of included studies. Moreover, due to the lack of reporting of sample characteristics, findings could not be interpreted regarding age, gender, and socio-economic background. Similarly, the lack of sufficient information about the healthcare, cultural and geographical settings within which the studies were conducted limited the comparative analysis. Nevertheless, this is the first review on this topic in the nursing and biomedical literature, and it has highlighted the particular experiences of adolescents with SCD and the consequent implications for research and nursing practice development. 


\section{Acknowledgement}

Brenda Agyeiwaa Poku is funded by a University of Manchester President's Doctoral Scholarship.

\section{References}

Adeyemo, T. A., et al. 2015. Health-related quality of life and perception of stigmatisation in adolescents living with sickle cell disease in Nigeria: A cross-sectional study. Pediatr Blood Cancer. 62:1245-1251

Ameringer, S., Smith, W.R., 2011. Emerging biobehavioral factors of fatigue in sickle cell disease. J Nurs Scholarsh. 43(1):22-29

Ameringer, S., et al. 2014. Fatigue in adolescents and young adults with sickle cell disease: Biological and behavioral correlates and health-related quality of life. J Pediatr Oncol Nurs. 31(1):6-17

Amr, M. A., et al. 2011. Health-related quality of life among adolescents with sickle cell disease in Saudi Arabia. Pan Afr Med J. 8(10)

Anie, K.A., et al. 2010. Psychosocial impact of sickle cell disorder: Perspectives from a Nigerian setting. Global Health. 6(2)

Anionwu E. N., Atkin, K. 2001. The politics of sickle cell disease and thalassaemia. Buckingham: Open University Press

Asnani, M. R., et al. 2014. Risky behaviors of Jamaican adolescents with sickle cell disease. Hematology, 19(7):373-379

Atoui, M., Badr, L.K., Brand, T D., Khoury, R., Shahine, R., Abboud, M., 2015. The daily experiences of adolescents in Lebanon with sickle cell disease. J Pediatr Health Care. 29(5):424-434

Babler, E., Strickland, C.J., 2016. Helping adolescents with Type 1 Diabetes "Figuring it out" J Pediatr Nurs. 31:123-131 
Barakat, L.P., et al. 2007. Negative thinking as a coping strategy mediator of pain and internalizing symptoms in adolescents with sickle cell disease. J Behav Med. 30:199-208

Benton, T.A., et al. 2011. Psychiatric diagnosis in adolescents with sickle cell disease: A preliminary report. Curr Psychiatry Rep. 13(111), 111-115 Doi:10.1007/s11920011-0177-3

Bettany-Saltikov, J. 2012. How to do a systematic literature review in nursing: a stepby-step guide. Maidenhead: McGraw-Hill/Open University Press.

Bhatt, K., et al. 2011. Knowledge and health beliefs of Jamaican adolescents with sickle cell disease. Pediatr Blood Cancer. 57:1044-1048

Brandow, A. M., et al. 2010. Vaso-occlusive painful events in sickle cell disease: Impact on child well-being. Pediatr Blood Cancer. 54(1):92-97

Britto, M.T., et al. 1998. Risky behavior in teens with cystic fibrosis or sickle cell disease: A multicenter study. Pediatrics. 101(2):250-256

Campbell, A.D., et al. 2010. Coming of age with sickle cell disease and the role of patient as teacher. J Natl Med Assoc. 102(11):1073-1078

Centre for Reviews and Dissemination (2009) Systematic reviews: CRD's guidelines for undertaking reviews in health care. [Online]. Available at:

https://www.york.ac.uk/media/crd/Systematic Reviews.pdf [Accessed on 15/11/15]

Clayton-Jones, D., et al. 2016. Spirituality and religiosity in adolescents living with sickle cell disease. West J Nurs Res. 38(6):686-703. Doi: 10.1177/0193945915625065.

Cotton, S., et al. 2009. Religious and spiritual coping in adolescents with sickle cell disease: A pilot study. J Pediatr Hematol Oncol. 31(5), 313-318

Dale, J.C., et al. 2011. Health-related quality of life in children and adolescents with sickle cell disease. J Pediatr Health Care. 25(4):208-215

Dampier, C., et al. 2002. Home management of pain in sickle cell disease: A daily diary study in children and adolescents. J Pediatr Hematol Oncol. 24(8):643-647 
Dennis-Antwi, J. A. et al. 2011. 'I can die today, I can die tomorrow': Lay perspectives of sickle cell disease in Kumasi, Ghana, at a point of transition. Ethn Health, 16 (4-5): pp. 465-481

Drutchas, A., Anandarajah, G., 2014. Spirituality and coping with chronic disease in pediatrics. Rhode Island Med J. [online]. Available at:

http://rimed.org/rimedicaljournal/2014/03/2014-03-26-spirituality-drutchas.pdf [Accessed on 22/12/16]

Dyson, S.M., et al. 2010a. Disclosure and sickle cell disorder: A mixed method study of young people with sickle cell at school. Soc Sci Med. 70:2036-2044

Dyson, S.M., et al. 2010b. Reported school experiences of young people with sickle cell disorder in England. Br Educ Res J. 36(1):125-142 DOI: 10.1080/01411920902878941

Dyson, S.M., et al., 2011. Sickle cell, habitual dys-positions and fragile dispositions: Young people with sickle cell at school. Sociol Health and Illn. 33(3):465-483 Erskine, R., 2011. Adolescent boys with sickle cell disease: A qualitative study. Clin Child Psychol Psychiatry. 17(1):17-31

Fitzhugh, C.D., et al. 2014. Hematopoietic stem cell transplantation for patients with sickle cell disease: Progress and future directions. Hematol Oncol Clin North Am. 28(6):1171-1185

Freud, S. 1999. The social construction of normality. Fam Soc. 80(4): 333-339

Forrester, A.B., et al. 2015. The lived experiences of adolescents with sickle cell disease in Kingston, Jamaica. Int J Qual Stud Health Well-being. 10:e28104 http://dx.doi.org/10.3402/qhw.v10.28104

Fosdal, M.B., 2015. Perception of pain among pediatric patients with sickle cell pain crisis. J Pediatr Oncol Nurs. 32(1):5-20

Gabe, J., et al. 2002. Living with asthma: The experiences of young people at home and at school. Soc Sci Med. 55:1619-1633

Graves, J.K., et al. 2016. Depression, Anxiety and Quality of Life in children and adolescents with sickle cell disease. Pediatr Nurs. 42(3):113-119 
Harrison, O. M., Koenig, G. H., Hays, C. J. et al. 2001. The epidemiology of religious coping: A review of recent literature. Int Rev Psychiatry, 13(2):86-93

Hawker, S., et al. 2002. Appraising the evidence: Reviewing disparate data systematically. Qual Health Res. 12(9):1284-1299

Helman, C. G. 2007. Culture, Health and Illness (5ed). New York: Oxford University Press

Hurtig A.L., Park, A.K., 1989. Adjustments and coping in adolescents with sickle cell disease. Ann N Y Acad Sci. 565:172-182

Ikefuna, A. N., et al. 2009. Clinical profile and home management of sickle cell-related pain: The Enugu (Nigeria) experience. Pediatr Hematol Oncol, 26(5):309-312

Jerrell, J.M., et al. 2011. Prevalence and treatment of depression in children and adolescents with sickle cell disease: A retrospective cohort study. The Prim Care Companion for CNS Disord. 13(2) doi: 10.4088/PCC.10m01063.

Jin J., Sklar, E. G., Min Sen Oh, V. et al. 2008. Factors affecting therapeutic compliance: A review of patient's perspective. Ther Clin Risk Manag. 4(1): 269-286

John-Olabode, S., et al. 2015. Adolescents with sickle cell anaemia: Experience in a private tertiary hospital serving a tertiary institution. Niger Med J. 56(3):204-207 DOI: $10.4103 / 0300-1652.160397$

Jamieson, N., et al. 2014. Children's experiences cystic fibrosis: A systematic review of qualitative studies. Pediatrics 133(6): e1683-e1697

Kagawa-Singer, M., Padilla, V. G., Ashing-Giwa, K. 2010. Health-related quality of life and culture. Semin Oncol Nurs. 26(1): 56-67

Kemp, M., et al. 2015. Are adolescents with sickle cell disease satisfied with their outpatient clinic experience? Arch Dis Child 100(Suppl 3): A169-A169

Key, J.D., et al. 2001. Depressive symptoms in adolescents with a chronic illness. Child Health Care. 30(4):283-292 
Kumar, S., et al. 1976. Anxiety, self-concept and personal and social adjustments in children with sickle cell anemia. J Pediatr. 88(5):859-863

Kyngäs, H., 2004. Support network of adolescents with chronic disease: Adolescents' perspective. Nurs Health Sci. 6:287-293

Lemanek, K. L., et al. 1986. Psychological adjustment of children with sickle cell anemia. J Pediatr Psychol. 11(3):397-409

Lukoo, R. N., et al. 2015. Depression in children suffering from sickle cell anemia. Journal of Pediatr Hematol Oncol. 37(1):20-24

Mackner, M. L., et al. 2004. Review: Psychological issues in pediatric in inflammatory bowel disease. J Pediatr Psychol. 29(4):243-257

Maikler, V. E., et al. 2001. Children's and adolescents' use of diaries for sickle cell pain. J Soc Pediatr Nurs. 6(40):161-169

Moher D. et al. 2009. Preferred Reporting Items for Systematic Reviews and MetaAnalyses: The PRISMA Statement. PLoS Med 6(7): e1000097. doi:10.1371/journal.pmed1000097

Morgan, S.A., Jackson, J., 1986. Psychological and social concomitants of sickle cell anemia in adolescents. J Pediatr Psychol. 11(3):429-439

Mufti, G., et al. 2015. Pakistani children's experiences of growing up with Betathalassemia major. Qual Health Res 25(3):386-396

Mulumba, L., Wilson, L., 2015. Sickle cell disease among children in Africa: An integrative literature review and global recommendations. Intl J Afr Nurs Sci. 3:56-64

Piel, F.B., et al. 2013. Global burden of sickle cell anaemia in children under five, 20102050: Modelling based on demographics, excess mortality and interventions. PLoS Med, 10(7): e1001404. DOI: 10.1371/journal.pmed.1001484

Rhee, H., et al. 2007. Adolescents' psychosocial experiences living with asthma: A focus group study. J Pediatr Health Care 21:99-107 
Ribeil, J-A., et al. 2017. Gene therapy in a patient with sickle cell disease. N Engl J Med. $376: 848-855$

Porter, J.S., et al. 2014. Transition from pediatric to adult care in sickle cell disease: Perspectives on the family role. J Pediatr Nurs. 29:158-167

Shakespeare, T. 1995. Back to the future? New genetics and disabled people. Critical Social Policy, 15:22-35

Shapiro, B.S., et al. 1995. Home management of sickle-related pain in children and adolescents: A natural history and impact on school attendance. Pain 61:139-144

Shenton, K. 2004 Strategies for ensuring trustworthiness in qualitative research projects. Educ for Info. 22(2):63-76

Suris, J., et al. 2004. The adolescent with a chronic condition. Part 1: Developmental issue. Arch Dis Child. 89:938-942

Taylor, R.M., et al. 2008. The experience of living with a chronic illness during adolescence: A critical review of the literature. J Clin Nurs. 17:3083-3091

Taylor, R.M., et al. 2013. Developing a conceptual model of teenage and young adult experiences of cancer through meta-synthesis. Intl J Nurs Stud. 50:832-846

Telfair, J., Gardner, M.M., 1999. African American adolescents with sickle cell disease: Support groups and psychological well-being. J Black Psychol. 25(3):378-390

Telfair, J., Gardner, M.M., 2000. Adolescents with sickle cell disease: Determinants of support group attendance and satisfaction. Health Soc Work. 25(1):43-50

Tunnicliffe, D. J., et al. 2016. Lupus means sacrifices: Perspectives of adolescents and young adults with systemic lupus erythematosus. Arthritis Care Res. 68(2):828-837

United Nations General Assembly, 2008. 'Sickle cell anaemia as a major public health problem http://www.un.org/press/en/2008/ga10803.doc.htm [Accessed on 13/05/16]

Valenzuela, J.M., et al. 2013. Understanding the experiences of youth living with sickle cell disease: a photovoice pilot. Fam Community Health. 36(2):97-108 
While, A. E., Mullen, J., 2004. Living with sickle cell disease: the perspectives of young people. Br J Nurs. 13(6):320-325

Whittemore R., Knafl, K. 2005. The integrative review: Updated methodology. J Adv Nurs. 52(5): 546-553

Yang, Y. M., et al. 1994. Depression in children and adolescents with sickle cell disease. Arch Pediatr Adolesc Med. 148(5):457-460 


\section{Tables}

Table 1 Review Search Terms

PEO tool Search terms

\begin{tabular}{ll}
\hline Population & "adolescen*" OR "teen*" OR "youth" OR "student*" \\
& OR "young people" OR "young person" OR "young \\
& adult*" OR "juvenile" OR "child*" OR "schoolchild*" \\
& OR "youngster*"OR "p?ediatric" \\
Exposure & "sickle cell disease" OR "sickle cell disorder" OR \\
& "sickle cell syndrome" OR "sickle cell an?emia" OR \\
& "h?emoglobinopath*" \\
Outcome & "experience*" OR "view*" OR "percep*" OR \\
& "perspective*" OR "concern*" OR "attitude*" OR \\
& "feel*" OR "understand*" OR "meaning*" OR \\
& "know*" OR "opinion* OR "perceive" OR "belie*"
\end{tabular}

Table 2 Inclusion and exclusion criteria

- $\quad$ Primary research

- Included adolescents with SCD aged 12-19 years or participants with a mean age within the 12 to 19 -year range. The age range was a pragmatic decision based on the literature on pubertal development in children with SCD and definitions of adolescence.

- If a study included other participants such as children younger than 12 years, adolescents with other forms of haemoglobinopathy or chronic illness, young people older than 19 years, adults and other family members, it was considered for inclusion if separate results were presented for the population of interest.

- Adolescents' own reported experiences 